\title{
Low cycle fatigue evaluation of NiTi SESMA thin wires
}

\author{
V. L. Sateesh, P. Senthilkumar, Satisha and G. N. Dayananda \\ Centre for Societal Missions and Special Technologies, CSIR-National Aerospace Laboratories, \\ Bangalore, India \\ Email: sateesh@nal.res.in
}

\begin{abstract}
This paper presents experimental studies on low cycle fatigue (LCF) life of super elastic shape memory alloy (SESMA) wires. The effect of frequency of the loading and amplitude of the strain on the fatigue life has been studied individually. Various loading frequencies have been considered to study the effect of frequency, by keeping the amplitude constant. From the experimental data, it was found that the low cycle fatigue life of the SESMA reduces with increase in the frequency. The effect of amplitude on the low cycle fatigue life of SESMA has also been studied and it was found that the SESMA cycled at lower net strain has more fatigue life than the one cycled at higher net strain. Further, the plastic strain accumulation is also more in the samples tested at the higher net strain loadings. The modulus of austenite is found to be by and large independent of the frequency and amplitude of the loading. Further, martensitic unloading modulus is same for all the minimum strain amplitudes.
\end{abstract}

\section{Nomenclature}

$\begin{array}{ll}\text { Af } & : \text { Austenite finish temperature } \\ \mathrm{A}_{\mathrm{s}} & : \text { Austenite starting temperature } \\ \mathrm{M}_{\mathrm{f}} & : \text { Martensite finish temperature } \\ \mathrm{M}_{\mathrm{s}} & : \text { Martensite starting temperature } \\ \varepsilon_{\max } & : \text { Maximum strain of the cycle } \\ \varepsilon_{\min } & : \text { Minimum strain of the cycle }\end{array}$

\section{Introduction:}

It is well known that the shape memory alloys (SMA) undergo phase transformation with the application of external stimuli. At high temperature this material is in austenite phase and the phase transformation to the lower temperature martensitic phase is effected either by reduction in the temperature or by applying the mechanical load. If the transformation takes place from austenite to matensite phase with the application of mechanical load, the transformation is referred to as stress induced transformation. In this kind of transformation, there are large recoverable strains $(8 \%$ to $10 \%)$ induced in the material. Hence, these transformations are also called as super elastic transformations. In many of the applications, 
super elastic shape memory alloys are used in the cyclic loading conditions. It was found that shape memory alloys subjected to cyclic loading, generate high density of dislocations in the martensitic variants before failure [1]. Eggeler et al. [2] have experimentally studied the structural and functional fatigue behavior of NiTi SESMA wires and concluded that the plateau stresses and the area of the stress-strain hysteresis decreases with increase in cycle number. Further, it has been found that the irreversible strain accumulates during strain controlled tension tests. Pieczyska et al. [3] have used infrared thermography for measuring the thermal signatures during mechanical cycling. The IR measurements were helpful in identifying the phase transformation in $\mathrm{Ni}-\mathrm{Ti}$ wires.

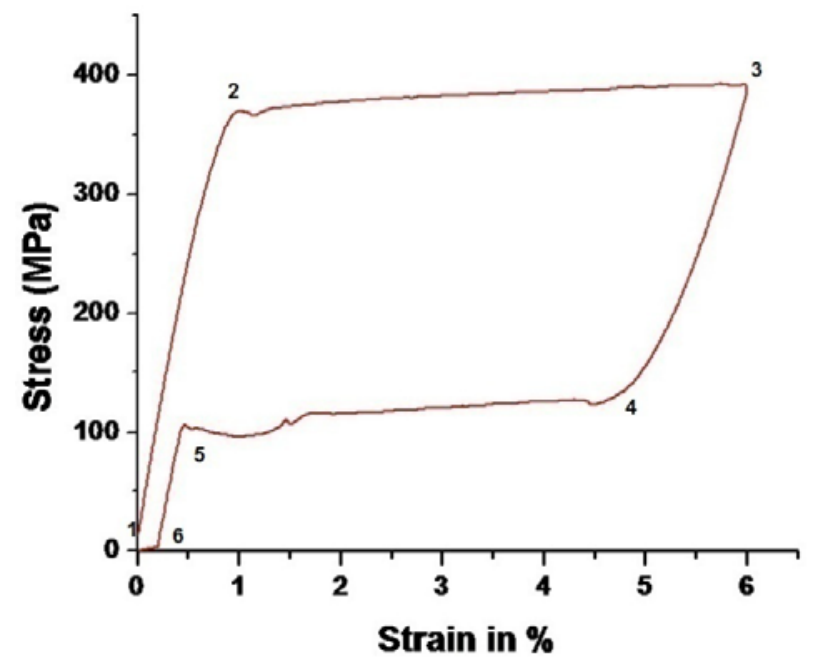

Figure 1 Typical hysteretic behavior of SESMA

Chen et al. [4] have studied the compressive stress-strain behavior of SESMA wires under quasi-static loading and high strain loadings. It was found that the plateau stress is strain-rate dependent. Heller et al. [5] have developed a testing procedure for thin wires under tension, torsion bending and combined loads. It has been concluded that the SESMA has good damping capabilities at low frequency loading. The effect of strain amplitude on fatigue life of the SESMA has been evaluated for $0.5 \mathrm{~Hz}$ frequency on dog-bone specimens by Maletta et al. [6]. It was observed from the experiments that there is a variation in fatigue life of the specimens for constant strain amplitude.

The stress-strain behavior of the super elastic material exhibits a hysteretic behavior as shown in the Figure 1. The initial austenitic elastic loading region is represented by the segment from point 1 to 2 . The stress induced forward transformation from austenite to martensite which is exothermic in nature is represented by the plateau segment from 2 to 3 . The region 
joining 3 to 4 is the martensitic unloading segment. The reverse transformation from martensite to austenite is endothermic in nature and is given by the segment 4 to 5 . Finally, the segment from point 5 to 6 represents the elastic unloading of the austenite. The super elastic transformation depends on the frequency (strain rate) of the loading and amplitude of the strain. The area of the hysteresis also reduces with the increase in the strain rate [7-11]. Nemat-Nasser and Guo [7] have studied the super elastic behavior of SMA for various annealing temperatures and strain rates under compressive loading. It was reported that the accumulated residual strain increases with increase in the number of cycles. Further, the dissipated energy reduces drastically in the first 100 cycles and then stabilizes.

It has also been observed that at the high loading rates, the segment from the reverse transformation plateau and martensite unloading merges [9]. Further, the matensite plateau stress (stress corresponds to 2 to 3 ) and the reverse transformation plateau stress (4 to 5) increases with increase in the strain rate. In addition, it was also found that there is a shift in the hysteresis behavior with change in frequencies. This is due to the fact that the transformation stress depends on the temperature of the wire. As the frequency/strain rate is higher, there is no time available for the wire to convect the latent heat of transformation.

From the experimental studies DesRoches et al [10] have found that the wire form of the SESMA exhibits more damping and strength properties than bars. Further, it is found that the damping property of the SESMA reduces with the increase in the strain rate.

The properties of shape memory alloys were observed to vary with the number of cycles [12] and found to stabilize after couple of hundred cycles. In the previous work [13], the present authors have estimated the fatigue life of SESMA based on the dissipated energy of the first few hundred cycles. The effect of ambient temperature, strain amplitude and frequency of loading on the damping behavior and loss factor for the SESMA under cyclic loading is studied experimentally by Piedboeuf and Gauvin [14]. It has been concluded from the study that the energy dissipation during the cyclic testing will decrease with increase in frequency if the frequency is above $0.1 \mathrm{~Hz}$. Further, the maximum dissipation is found in the $0.1 \mathrm{~Hz}$ frequency. In addition, the ambient temperature has negligible effect on the dissipative energy. In Ref. [15], cyclic studies have been carried out on thin tubes. The transformation temperature and deformations have been recorded on these tubes using IR cameras and video extensometer. It is observed from the thermal imaging that during the austenite deformation stage, there is a homogeneous temperature distribution over the tubes and the transformation is inhomogeneous. Many researchers have studied the fatigue behavior of SESMA [13-17]. 
The prediction of fatigue failure of SESMA has also been attempted by using acoustic emission technique [17].

This paper focuses on the experimental investigations on low cycle fatigue life of SESMA subjected to various frequencies and net strain amplitudes. In addition, the effect of frequency and amplitude of strain on the plastic strain have also been studied. The plastic strain accrues largely due to slip between the cell boundaries [17]. To study the effect of net strain amplitudes on low cyclic fatigue life, the minimum strain amplitude $\left(\varepsilon_{\min }\right)$ of the cycle is varied by keeping the maximum strain $\left(\varepsilon_{\max }\right)$ of the cycle as constant at $6 \%$. The details of the experiment are as follows.

\section{Experimental details:}

The composition of the wire considered for this study is $54.3 \% \mathrm{Ni}$ and $45 \%$ Ti by weight. The diameter of the wire considered for the testing is $0.6 \mathrm{~mm}$. Before the test, the sample is heat treated at a temperature of $500^{\circ} \mathrm{C}$ for $15 \mathrm{~min}$ and then water quenched. The transformation temperatures of the wire are found to be $\mathrm{M}_{\mathrm{f}}=6.8^{0} \mathrm{C}, \mathrm{M}_{\mathrm{s}}=12.5^{0} \mathrm{C}, \mathrm{A}_{\mathrm{f}}=17.7^{0} \mathrm{C}$ and $\mathrm{A}_{\mathrm{s}}=11.9^{\circ} \mathrm{C}$ and the corresponding DSC report of the specimen is shown in Figure 2.

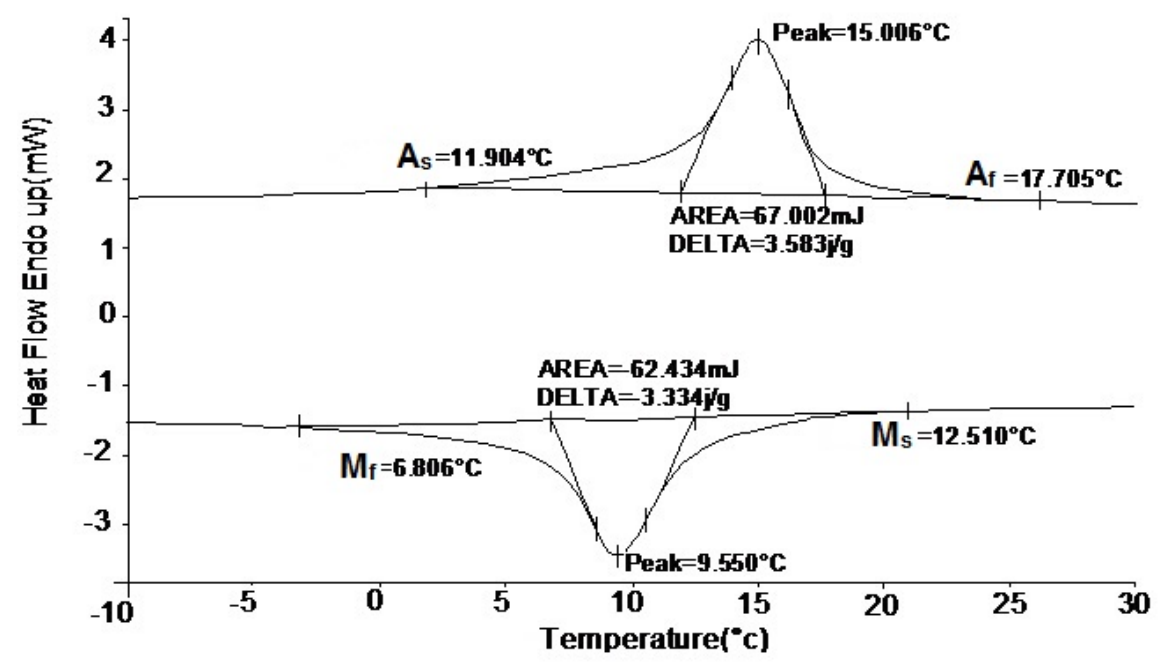

Figure 2 DSC report for $0.6 \mathrm{~mm}$ dia. wire

Tension- tension cyclic tests have been carried out to study the low fatigue behavior of the super elastic shape memory alloy wires. The experiments have been performed on the computer controlled thermo-mechanical fatigue (Bose Electroforce 3330) testing machine in 
displacement control mode. This is because the wire will bend as the sample is thin, if clip on extensometer is mounted on sample. Hence, the extension of the wire is taken as the cross head movement and the strain is calculated as ratio of extension of the wire with the original gauge length. To maintain the constant and uniform ambient temperature, the entire tensile testing equipment is housed in a temperature controlled chamber. The temperature is maintained at $22 \pm 0.5^{0} \mathrm{C}$ during the testing which is well above the austenite finish temperature of $17.7 \mathrm{deg}$. C. The fatigue life of SESMA wires is evaluated under two different loading conditions. In the first set of constant amplitude experiments (strain range $1.5 \%$ to $6 \%$ ), the frequency is varied. For the second case, the frequency of the testing is kept constant at $0.1 \mathrm{~Hz}$ and the minimum strain amplitudes are varied (from 0 to $3 \%$ ) while the maximum strain amplitude is fixed at $6 \%$. Therefore, the net strain amplitudes are varied from $6 \%$ to $3 \%$. In both the cases, the sinusoidal wave form of the displacement is considered. The low cycle fatigue testing has been carried out until the sample fails.

\section{Results and discussion}

The resulting stress-strain behavior and fatigue life of the super elastic shape memory alloys subjected to various frequencies and amplitudes are described below. The plastic strain produced during each cycle is also calculated and given.

\subsection{Effect of frequency on low cycle fatigue life}

The effect of frequency on the low cycle fatigue life has been studied by testing the specimen at various frequencies keeping the strain constant. The frequencies considered for the testing are $0.01,0.05,0.1,1,5,10,20,25$ and $30 \mathrm{~Hz}$. The strain amplitude range is kept constant (i.e. $1.5 \%$ to $6 \%$ ). The cyclic stress-strain behavior forms a hysteresis loop and the resulting relation is shown in the Figure 3 for $0.01 \mathrm{~Hz}$ loading frequency for first three cycles. The corresponding displacement input signal for the first three cycles is shown in the Figure 4. This figure demonstrates the loading procedure. The steps followed to induce the desired strain range for cycling is as follows; initially the strain is taken to the level of $6 \%$ then reduced to a minimum strain of $1.5 \%$ and oscillated between $1.5 \%$ to $6 \%$ strain for three cycles. 


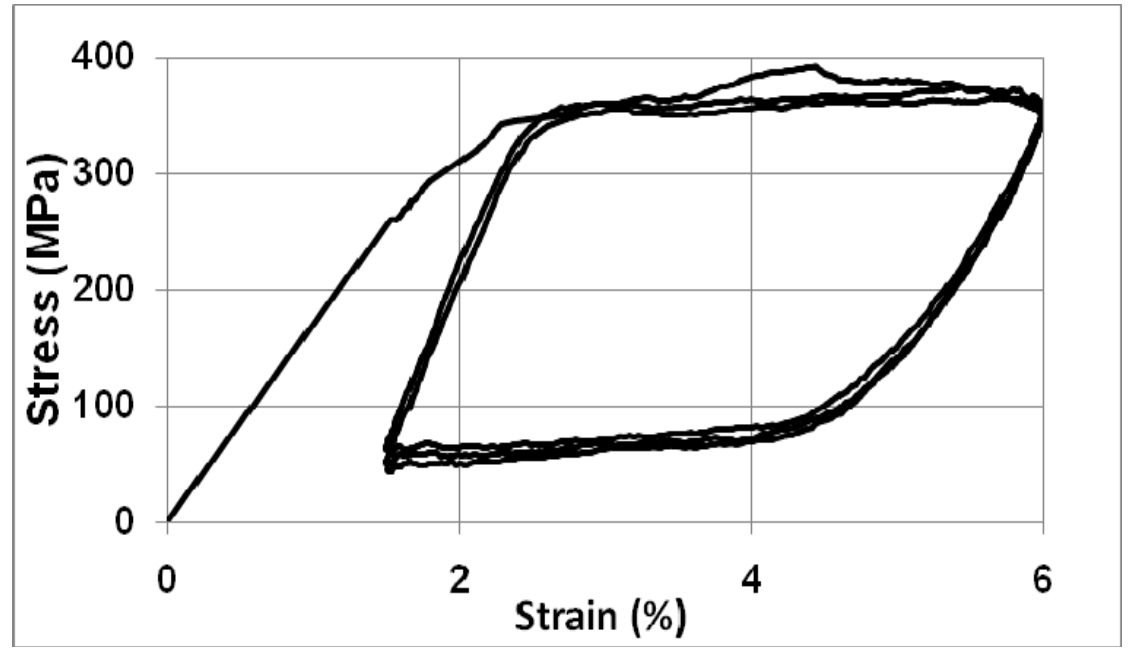

Figure 3 Stress-strain relation of SESMA at $0.01 \mathrm{~Hz}$

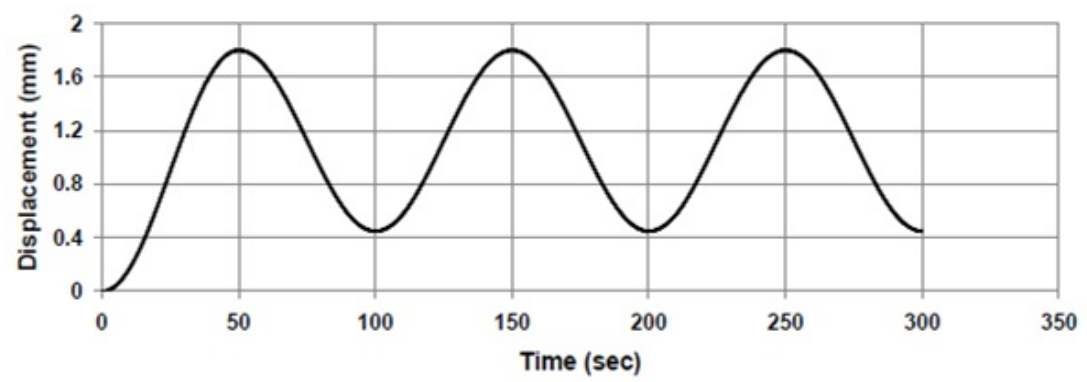

Figure 4 Input displacement signal for $1.5 \%$ to $6 \%$ strain amplitude

The minimum strain amplitude is considered as $1.5 \%$ to keep the test specimen straight during the cycling by absorbing the plastic strain. The stress-strain relation for the frequencies $0.01,0.1,1,10,20$ and $30 \mathrm{~Hz}$ is given in the Figure 5. To plot the stress strain relations, the data corresponding to the first cycle, wherein, the strain amplitude between 1.5 to $6 \%$ is considered. From the Figure 5, the area of the hysteresis loop for various frequencies has been calculated and given in the Table 1. The area of the hysteresis is higher for the frequency corresponding to $0.1 \mathrm{~Hz}$ when compared to $0.01 \mathrm{~Hz}$. It can be seen that the area of the hysteresis loop decreases with increase in the frequency from $0.1 \mathrm{~Hz}$. Further, it also can be seen that the area of the hysteresis loop significantly reduces once the frequency crosses $10 \mathrm{~Hz}$. Similar observations can also be found in the Ref. [5], [15]. In addition, the austenite modulus at various frequencies is also given in the Table 1. It can be seen from the Table 1 that the variation of austenite modulus with the frequency is very less in the tested range of frequencies. In the literature ([13], [15]), the austenite modulus is reported as 20 to $50 \mathrm{GPa}$. In the Ref. [13], the austenite modulus is calculated by considering the strain from the cross head movement and is given as $25 \mathrm{GPa}$. The slope of the martensite transformation plateau 
increases with increase in the frequency. The reason behind this is the transformation stresses increase with increase in the temperature. The area of the hysteresis indicates the energy dissipated in that cycle in the form of heat. At the high frequencies, the time available for heat transfer from the wire is less when compared to the samples tested under low frequencies [19]. This causes heat buildup on the wire and hence, the transformation temperature will also rise which in turn leads to increase in the slope of the martensitic plateau. Similar observation has been reported in Refs. [14] and [20]. The reverse transformation plateau is also a function of frequency. In case of the high frequency loading, the martensitic unloading and reverse transformation are inseparable (per eg. $35 \mathrm{~Hz}$ ); hence there is no distinct difference between reverse transformation plateau and martensitic unloading [7].

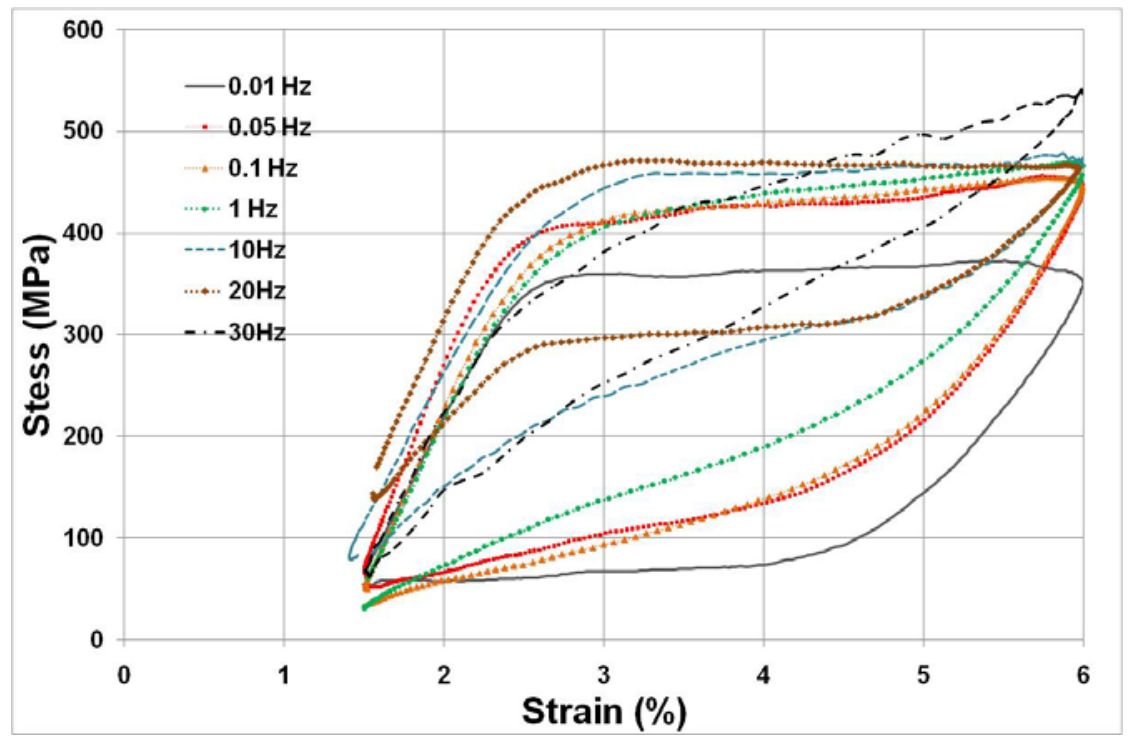

Figure 5 Hysteresis loops of SESMA for various frequencies

Table 1 Area of the hysteresis and austenite modulus for the first cycles subjected to various frequencies

\begin{tabular}{|c|c|c|c|c|c|c|}
\hline Frequency & 0.01 & 0.1 & 1.0 & 10 & 20 & 30 \\
\hline $\begin{array}{c}\text { Area of } \\
\text { hysteresis } \\
\text { N-mm }\end{array}$ & 997.5 & 1010.9 & 788.4 & 628.7 & 593.2 & 427.4 \\
\hline $\begin{array}{c}\text { Austenite } \\
\text { modulus (GPa) }\end{array}$ & 31.25 & 33 & 32.5 & 31.25 & 33.33 & 32.5 \\
\hline
\end{tabular}


The cumulative plastic strain corresponding to each cycle until the failure is shown in the Figure 6. This plot gives an indication about shift of the hysteresis loop at the $\mathrm{n}^{\text {th }}$ cycle when compared to the first cycle. The net plastic strain of each cycle can be calculated by the difference in the cumulative plastic strain of two consecutive cycles. From the Figure 6, it can be seen that the major plastic strain accumulation is from the first 500 cycles. As can be seen from the figure at lower frequencies $(0.01 \mathrm{~Hz}$ for eg.) the stabilized plastic strain remains more are less constant after 500 cycles. However at the higher frequencies i.e. above $10 \mathrm{~Hz}$, the plastic strain does not stabilize until the failure. The similar observation is found in a previous study [15]. Further, accumulation of plastic strain is less at $30 \mathrm{~Hz}$ frequency when compared with the frequencies up to $20 \mathrm{~Hz}$. The reasons can be explained as follows. The deformation of the wire is due to three phenomena, viz; distortion of the austenite phase, phase transformation and slip in the cells boundaries.

In the sample tested above $20 \mathrm{~Hz}$ frequency, there is inadequate time available for the complete transformation as compared to lower frequency loading. The martensitic variants that are not transformed and there by trapped within the austenitic phase will not contribute to the reverse transformation. The strain due to the entrapped martensitic variants manifests as slip which in turn results in plastic strain in the material. Part of this plastic strain can be recovered by applying the heat to the sample. In case of frequencies higher than $20 \mathrm{~Hz}$, there is inadequate time for the latent heat to dissipate from the sample (as already stated), which results in heating up the sample. This heat helps in recovering the plastic strain of the sample to some extent. Hence, $30 \mathrm{~Hz}$ and $35 \mathrm{~Hz}$ frequencies loading show less accumulation of plastic strain than that of the frequency with $20 \mathrm{~Hz}$. After about 40 cycles the plastic strain recovers due to the heat build up on the wire. This can be clearly seen in the Figure 7 where, the cumulative plastic strain for 25,30 and $35 \mathrm{~Hz}$ are plotted. 


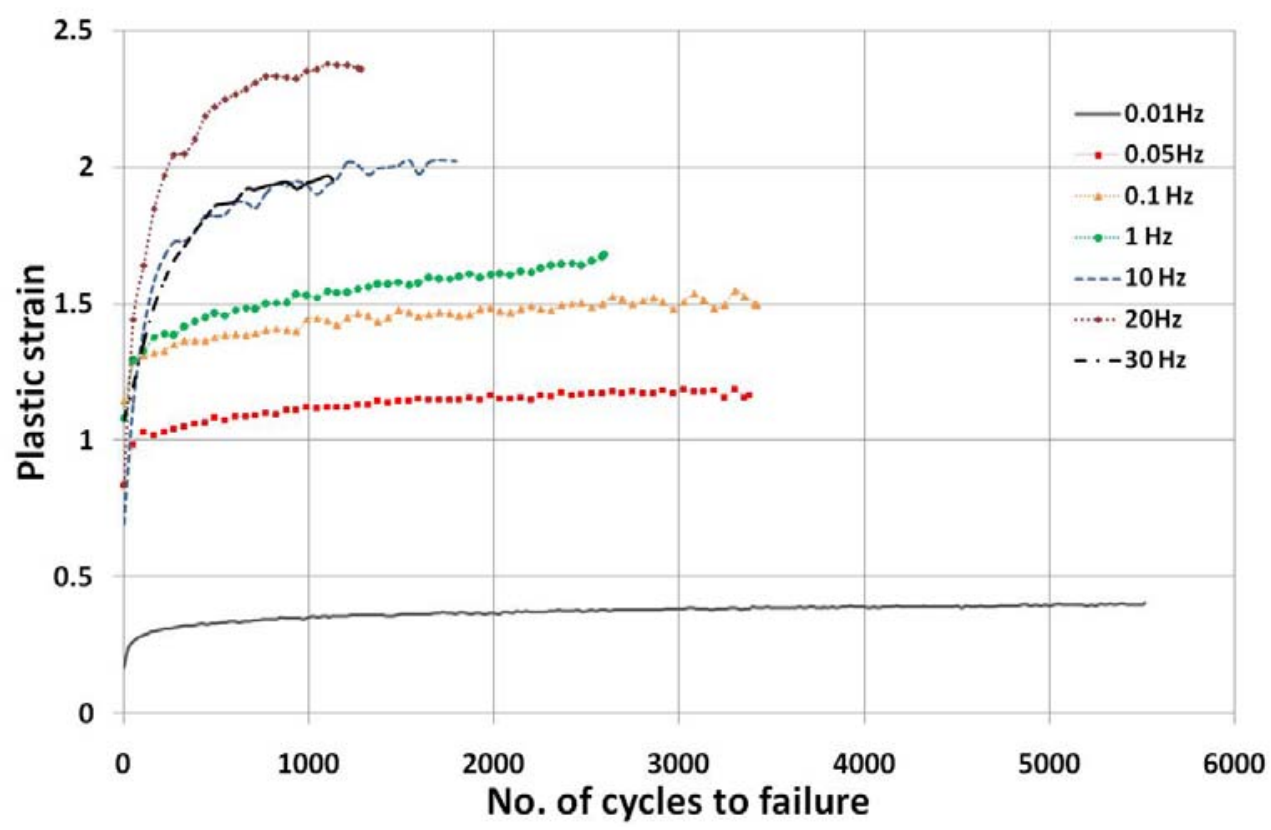

Figure 6 Relation between cumulative plastic strain with number of cycles

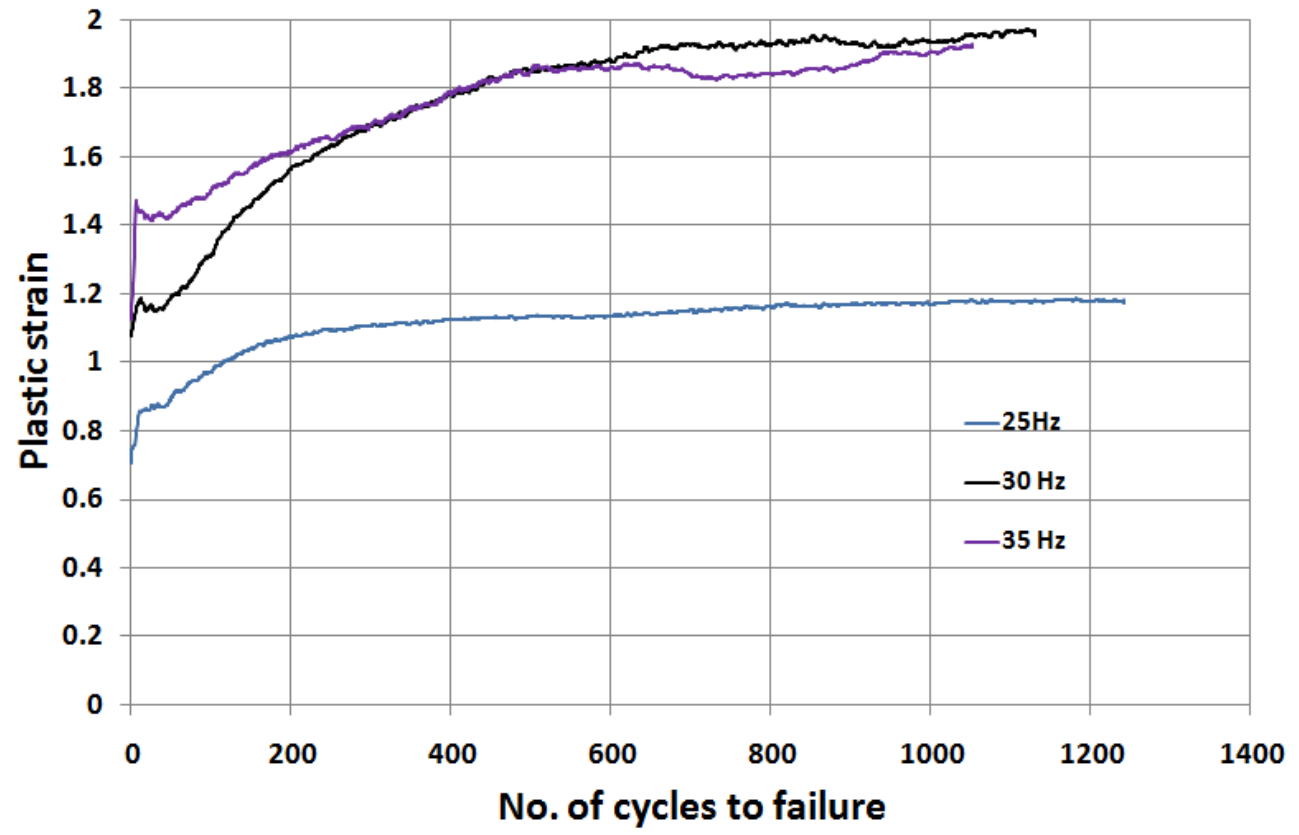

Figure 7 Relation between cumulative plastic strain with number of cycles till failure for the frequencies of 25,30 and $35 \mathrm{~Hz}$ 


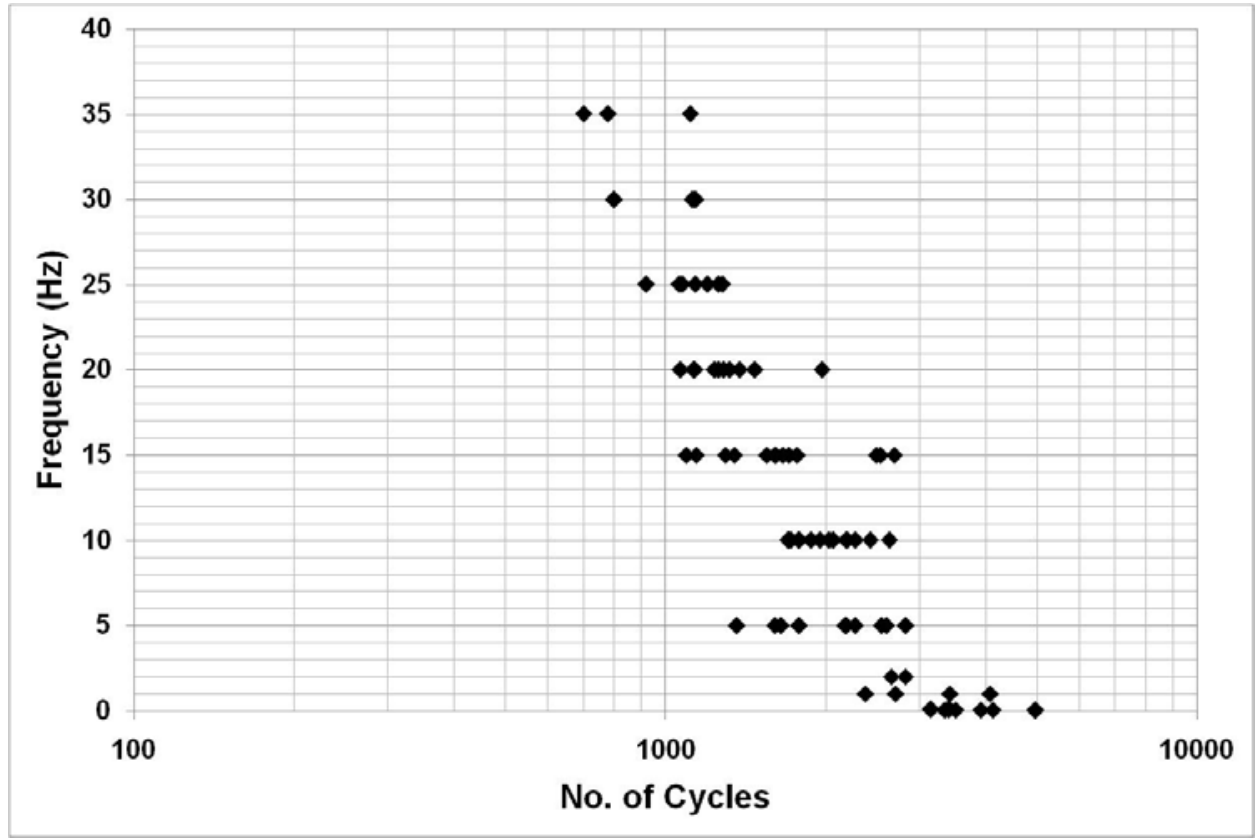

Figure 8 The relation between the frequency and No. of cycles to failure

The relation of low cycle fatigue life of SESMA with the frequency is shown in the Figure 8 [13]. It can be seen that the frequency of the loading reduces the low cycle fatigue life of the SESMA. The extent of phase transformations is partial when the sample is subjected to higher frequencies. The untransformed phases could give rise to slip driven dislocations in the sample. These dislocations could possibly act as high stress zones leading to propagation of the crack and consequently contribute to the failure at the lower number of cycles.

\subsection{Effect of amplitude on low cycle fatigue life}

The effect of amplitude on the fatigue life of SESMA is studied by limiting the maximum strain amplitude at $6 \%$ and the minimum strain is varied to different amplitude levels. The procedure to induce the desired strain range for cycling is as follows; initially the strain is taken to the level of $6 \%$ then reduced to a minimum strain of $1.5 \%$ and oscillated between $1.5 \%$ to $6 \%$ strain until the failure. The frequency considered for the testing is $0.1 \mathrm{~Hz}$. The typical input displacement and corresponding stress-strain relation is shown in the Figure 4 and Figure 3, respectively. Similarly the cycling is carried out at different minimum strain levels, namely, $0,0.5,1 \%, 1.5 \%, 2 \%$ and $3 \%$. The difference in the maximum strain and the 
minimum strain is referred as net strain, i.e. $\varepsilon_{\max }-\varepsilon_{\min }$, where, $\varepsilon_{\max }$ is the maximum strain and $\varepsilon_{\min }$ is the minimum strain of the cycle.

The resulting stress-strain relation for various strain amplitudes is given in the Figure 9. It can be seen that the slope of the martensitic plateau is same for the all strain amplitudes in the tested range. The variation of the austenite modulus is almost negligible for all the amplitudes. The path of the martensitic unloading and reverse transformation are same for all the amplitudes except for amplitudes $0.5 \%$ to $6 \%$ and $1.5 \%$ to $6 \%$ until reloading takes place. Further, the specimen cycled in the strain range 0 to $6 \%$ (net strain:6\%) shows more plastic deformation compared to the specimen cycled in the strain range of $1 \%$ to $6 \%$ and other samples cycled at the lower net strains.

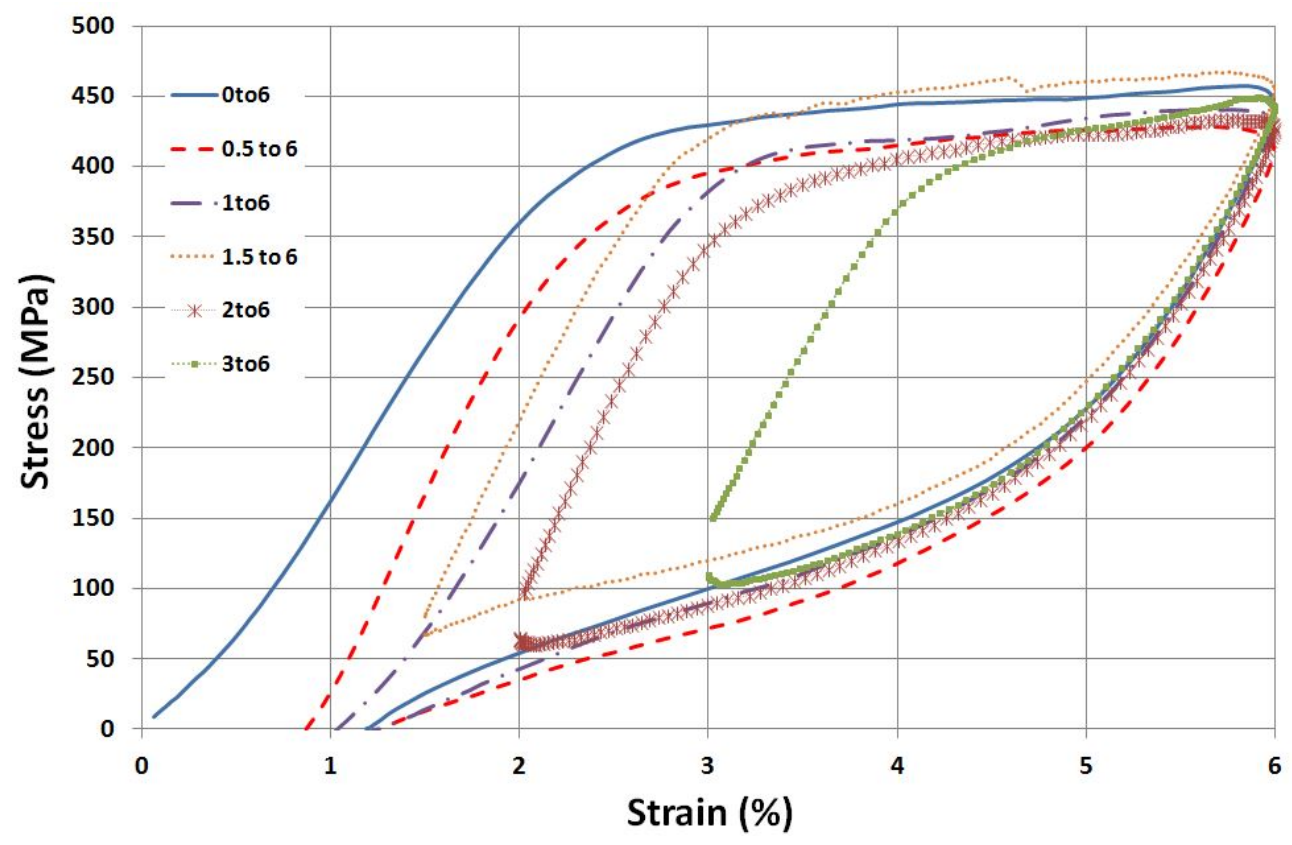

Figure 9 Stress-strain relation of SESMA subjected with various amplitudes of strains under $0.1 \mathrm{~Hz}$ frequency loading

The shift in the hysteresis loops on the strain axis for 0 to $6 \%, 1 \%$ to $6 \%, 1.5 \%$ to $6 \%, 2 \%$ to $6 \%$ and $3 \%$ to $6 \%$ with respect to the first cycle (cumulative plastic strain) is shown in the in the Figure 10. It can be seen that the samples tested with lower net strains viz; 5\%, 4.5\%, 4\% and $3 \%$ show a stabilized behavior after first 50 cycles, whereas in the case of 0 to $6 \%$ loading, there is a shift observed until the failure of the wire. In addition, the accumulation of plastic strain for the sample with the strain range $6 \%$ (i.e. $0-6 \%$ strain) is several orders more 
than that of the samples with low net strain amplitudes. Further, the samples tested with net strains less than $4.5 \%$ develop same plastic strain amplitude. If the net strain increases more than $4.5 \%$, the plastic strain also increases. In most of the literature $[9,10]$, studies have been carried out to relate the maximum strain to the plastic strains. From this study, it can be seen that the plastic strain accumulation is not only function of maximum strain amplitude but also a function of minimum strain (which needs to be judiciously chosen).

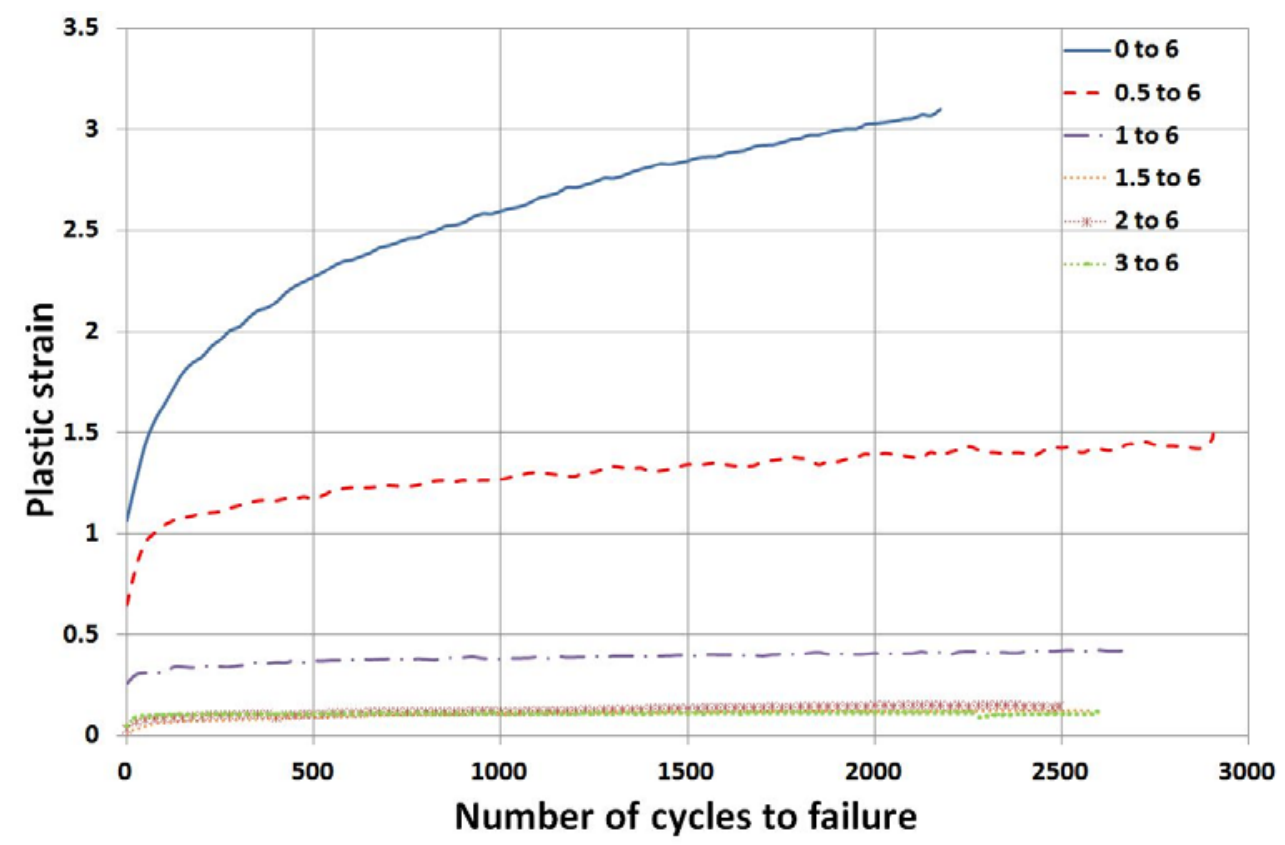

Figure 10 Cumulative plastic strain accumulated during the cyclic loading

Similar observations can also be made from the Figure 11, where, the hysteresis loops for various amplitudes of strains have been plotted for $500^{\text {th }}$ cycle. This cycle is considered to study the stress strain relation after the stabilization. It can be seen from Fig. 11 that the transformation stress reduces due to the accumulation of slip induced deformations [17]. These slip induced deformations lead to stress concentration pockets, which aids in reducing the critical stress to trigger the transformations. It is very clear from the Fig. 11 that the critical transformation stress reduces with increase in number of cycles. Further, it can be seen from the same figure that the slope of the martensite plateau increases due to the strain hardening effect caused by accumulation of dislocations with number of cycles. The implication of this is a reduction in the area of the hysteresis with increase in the number of cycles. 


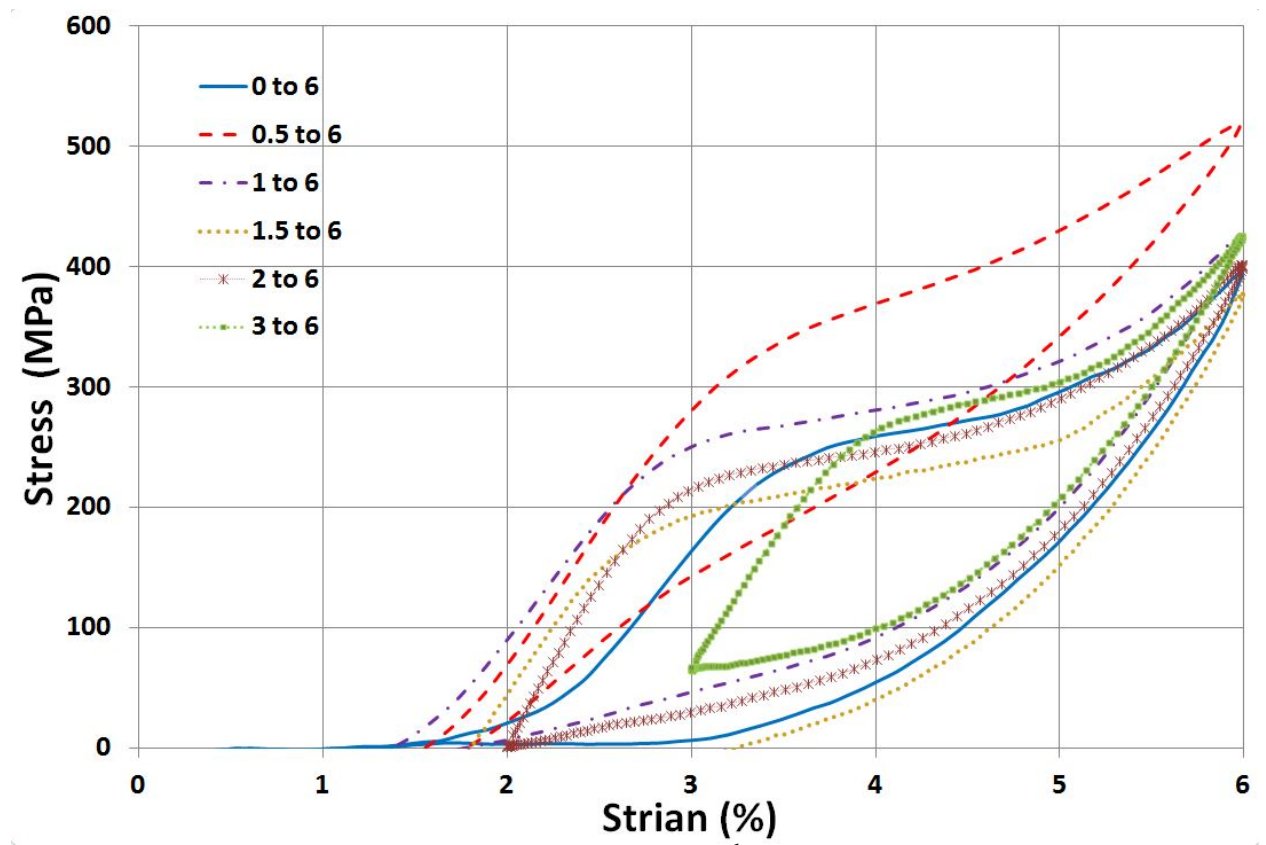

Figure 11 Stress-strain relation of SESMA at $500^{\text {th }}$ cycle subjected to $0.1 \mathrm{~Hz}$ frequency

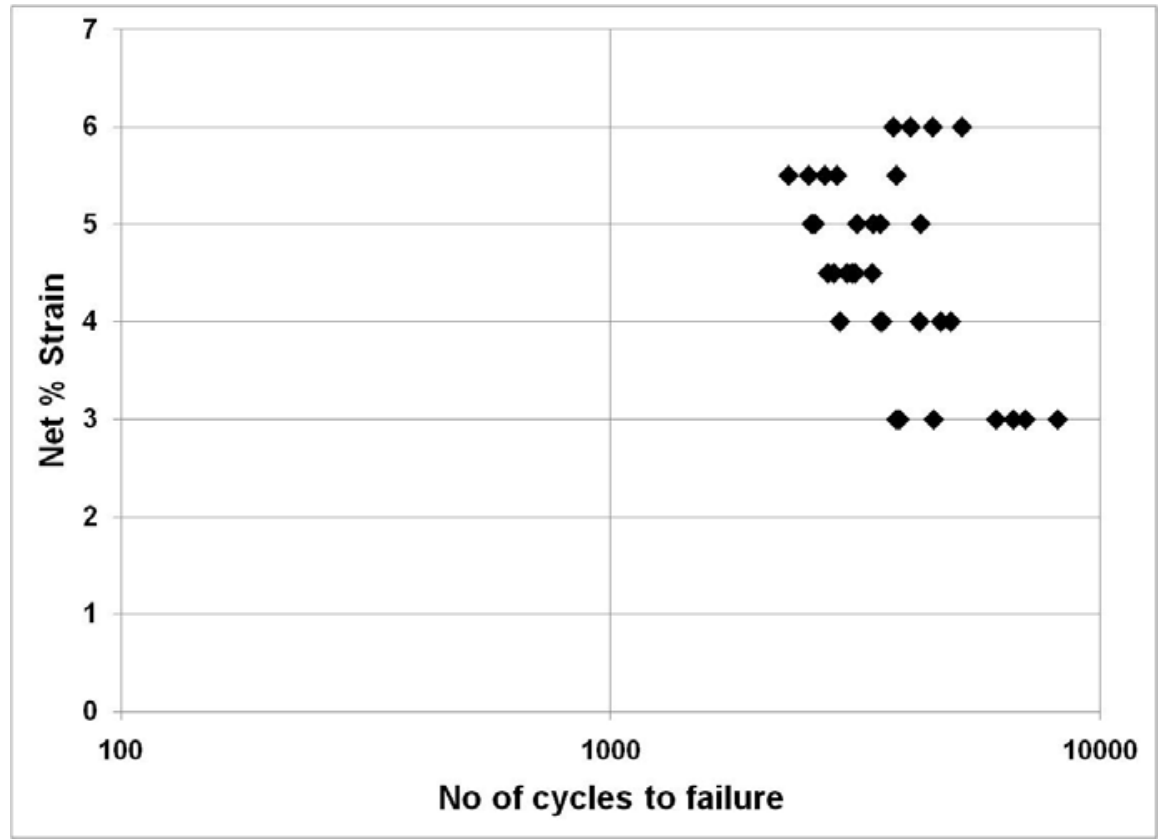

Figure 12 Net strain versus no. of cycles to fail

Figure 12 shows the relation between net strain versus the number of cycles to failure. It can be seen from the figure that the specimens cycled at lower net strains show more life cycles, except for the specimen tested at the strain varying from 0 to $6 \%$ (6\% net strain). This can be 
attributed to the fact that the cumulative plastic strain of the sample tested with $6 \%$ net strain strain is much higher than that of the sample where the strain is varied from $1 \%$ to $6 \%$ (i.e 5 $\%$ net strain). The initial plastic strain in the very first cycle reduces the effective straining of the sample. Hence, the life of the sample with net strain of $6 \%$ is higher compared with the sample cycled at $5 \%$ net strain.

\section{Conclusions:}

Low cycle fatigue life of super elastic shape memory thin wires is studied experimentally for various loading conditions such as frequency and amplitude of the loading. The effect of frequency on the low cycle fatigue life is studied by keeping the amplitude of the strain constant and varying the frequencies. It was found from the study that the low cycle fatigue life of SESMA reduces with increase in the frequency. Further, the austenitic modulus is largely independent of the frequency. However, the martensitic plateau changes its shape and slope with the change of frequency. In addition, reverse transformation plateau is a function of frequency. In case of the higher frequency loadings, the martensitic unloading is coupled with the reverse transformation plateau.

The effect of strain amplitude has also been studied by varying the minimum strain and keeping the maximum amplitude and frequency constant. It was observed from the experimental data that the samples with high net strains show more plastic strains and consequently have less number of cycles to failure. The austenitic modulus and the martensitic unloading are insensitive to the minimum strain. 


\subsection{References:}

1. Liu Y, Xie Z and Humbeeck J V, Cyclic deformation of NiTi shape memory alloys, Materials Science and Engineering A, Vol. 273-275, 1999, pp. 673-678.

2. Eggeler G, Hornbogen E, Yawny A, Heckmann A and Wagner M, Structural and functional fatigue of NiTi shape memory alloys, Materials Science and Engineering A, Vol. 378, 2004, pp. 24-33.

3. Pieczyska E A, Gadaj S P, Nowack W K and Tobushi H, Thermomechanical investigation of martensitic and reverse transformations in TiNi shape memory alloy, Bulletin of the Polish academy of sciences - Technical sciences, Vol. 52, No. 3, 2004 pp. 165-171.

4. Chen W W, Wu Q P, Kang J H, and Winfree N A, Compressive superelastic behavior of a NiTi shape memory alloy at strain rates of 0.001-750 s $\mathrm{s}^{-1}$, International Journal of Solids and Structures, Vol. 38, 2001, pp. 8989-8998.

5. Heller L, Kujawa A, Sittner P, Landa M, Sedlák P and Pilch J, Quasistatic and dynamic functional properties of thin superelastic NiTi wires, The European Physical Journal Special Topics, Vol. 158, 2008, pp. 7-14.

6. Maletta C, Sgambitterra E, Furgiuele F, Casati R, and Tuissi A, Fatigue of pseudoelastic NiTi within the stress-induced transformation regime: a modified Coffin-Manson approach, Smart materials and structures, Vol. 21, 2012, pp. 1-7.

7. Nemat-Nasser S and Guo W G, Superelastic and cyclic response of NiTi SMA at various strain rates and temperatures, Mechanics of Materials, Vol. 38, 2006, pp. 463-474.

8. Osman E. O. and Stefan H., A temperature and strain rate dependent model of NiTi shape memory alloys for seismic control of bridges, Proc. of SPIE, Vol. 7292, pp. 729241729253.

9. Dayananda G N and Subba Rao M, Effect of strain rate on properties of superelastic NiTi thin wires, Materials Science and Engineering A, Vol. 486, 2008, pp. 96-103.

10. DesRoches R, McCormick J and Delemont M, Cyclic properties of superelastic shape memory alloy wires and bars, Journal of Structural Engineering, Vol. 130, No. 1, 2004, pp. 38-46.

11. Lin $\mathrm{P} \mathrm{H}$ and Tobushi $\mathrm{H}$, Influence of strain rate on deformation properties of NiTi shape memory alloy, JSME International Journal A, Vol. 39, No. 1, 1996, pp. 117-123.

12. Choi E, Nam TH, Chung YS, Variation of mechanical properties of shape memory alloy bars in tension under cyclic loading, Material science and Engineering A, Vol. 527, 2010, pp. 4412-4417. 
13. V. L. Sateesh, Senthilkumar P, Satisha, G. N. Dayananda, A posteriori processing for estimation of low cycle fatigue failure in SMA wires, Journal of Material Science \& Engineering A, Vol. 594, 2014, pp. 212-217.

14. Piedboeuf M C and Gauvin R, damping behaviour of shape memory alloys: strain amplitude, frequency and temperature effects, Journal of Sound and Vibration, Vol. 214, No. 5, 1998, pp. 885-901.

15. D. Favier, H. Louche, P. Schlosser, L. Orgéas, P. Vacher, L. Debove, Homogeneous and heterogeneous deformation mechanisms in an austenitic polycrystalline $\mathrm{Ti}-50.8$ at.\% Ni thin tube under tension. Investigation via temperature and strain fields measurements, Acta Materialia, Vol. 55, 2007, pp. 5310-5322.

16. Moumni Z, Van Herpen A and Riberty P, Fatigue analysis of shape memory alloys: energy approach Smart Materials and Structures, Vol. 14, 2005, 287.

17. Dunand-Châtellet $\mathrm{C}$ and Moumni Z, Experimental analysis of the fatigue of shape memory alloys through power-law statistics, International journal of fatigue, Vol. 36, 2012, pp. 163-170.

18. Liu Y, Xiang. J, Apparent modulus of elasticity of near-equiatomic NiTi, Journal of Alloys and Compounds, Vol. 270, 1998, pp. 154-169.

19. Iadicola M A and Shaw J A, Rate and thermal sensitivities of unstable transformation behavior in a shape memory alloy, International Journal of plasticity, Vol. 20, No. 4-5, 2004, pp. 577-605.

20. Morin C, Moumni Z and Zaki W, Thermomechanical coupling in shape memory alloys under cyclic loadings: Experimental analysis and constitutive modelling, International Journal of Plasticity, Vol. 27, No. 12, 2011, pp. 1959-1980.

\section{Acknowledgements:}

The authors wish to express sincere gratitude to Aeronautical Research \&Development Board, DRDO for supporting this project. They also wish to express thanks to Mr. Shyam Chetty, Director, CSIR-NAL for his encouragement. Authors express their thanks to Prof. M S Sivakumar, Dept. of applied science, IITM for his guidance. 